\title{
Considerations in Dealing with Ethical Conflict Encountered in Healthcare Reform: Perceptions of Nurse Leaders
}

\author{
Robert Cooper $^{1}$, Garry Frank ${ }^{1}$, Cherry Shogren ${ }^{2}$ \\ ${ }^{1}$ College of Business and Public Administration, Drake University, Des Moines, USA \\ ${ }^{2}$ Professional Development, Unity Point Health-Des Moines, Des Moines, USA \\ Email: robert.cooper@drake.edu
}

Received 18 July 2014; revised 22 August 2014; accepted 17 September 2014

Copyright (C) 2014 by authors and Scientific Research Publishing Inc.

This work is licensed under the Creative Commons Attribution International License (CC BY). http://creativecommons.org/licenses/by/4.0/

(c) (i) Open Access

\begin{abstract}
With the nursing profession continuing to face an array of ethical issues, the article reports the findings of a survey of members of the American Organization of Nurse Executives conducted in 2012 to determine the extent to which nurse leaders at different organization levels perceive various factors in their personal, professional and organizational environments to be helpful in resolving ethical dilemmas. After their personal values, nurse leaders perceive factors related to their organization to be more helpful than those related to their profession, including, among others, the American Nurses Association Code of Ethics. The two highest rated business-related factors deal with the absence of pressure to compromise one's own ethical standards which suggests that one way healthcare organizations can assist nurses and their leaders is by neither explicitly nor implicitly pressuring them to go against their own ethical values. Other key factors related to the organization include formal organizational factors such as the existence of an ethics committee or a person to whom unethical activity can be reported as well as more informal factors related to organizational climate such as the actions and responsiveness of one's immediate boss, the ability to go beyond one's boss if necessary, the organizational culture, management philosophy, and management's communication of appropriate ethical behavior. Comparison of the findings of the 2012 survey with those of a similar study conducted in 2000 indicated the four factors perceived as most helpful in both studies were identical with the same rank order and the top-10 factors were identical with some differences in ranking. Further analysis indicated the relative degree of helpfulness of the 17 help factors common to both studies was perceived by responding nurse leaders as quite similar overall. The authors also discuss the implications for the profession and the healthcare industry today and in the future.
\end{abstract}

\section{Keywords}

Ethical Culture, Ethics Committee, Nursing Ethics, Patient Satisfaction, Quality of Care 


\section{Introduction}

As is commonly the case with professionals working in organizations in general, behavior and decision making of members of the nursing profession employed by hospitals or other types of healthcare organizations (HCOs) are influenced by factors related to their individual, organizational and professional environments [1]. Research indicates that when the personal and professional ethical values of professional employees are not congruent with those of their organization and they are pressured by management to go against their values, individual-organizational and professional-organizational conflicts result [2] [3].

During the period of the severe nurse shortage lasting approximately a decade from the decline of managed care in the mid-1990s, nurses experienced major conflict between their professional values focused on various aspects of quality patient care and organizational values related to cost control emphasized by the HCOs that employed them. The outcome of this conflict saw numerous proposals by the nursing profession to improve the quality of care overwhelmed by the strength of HCO's seemingly unconditional focus on cost control. Among the steps taken by HCOs to lower the cost of delivering care were reduced staffing which led to increased patient loads, mandatory overtime, inadequate administrative support, overwhelming stress, less competitive wages, hazardous working conditions, and reduced support services for patient care that ultimately caused reduced organizational commitment and job satisfaction along with higher turnover [4].

In recent years, governmental and nongovernmental payers have increasingly demanded that HCOs raise their standards for patient care, safety and satisfaction while continuing their efforts to reduce the cost of healthcare [5] [6]. Since failure to do so has already had a negative impact on HCOs' reimbursements for services provided or opportunities to qualify for quality bonuses, hospitals are taking steps to implement and assess the performance of a variety of initiatives aimed at improving quality of care, safety and patient satisfaction [7]-[9]. In broadening their organizational objectives beyond their traditional heavy emphasis on cost reduction to also include giving serious consideration to factors reflecting professional and personal values of critical importance to nurses, HCOs have created an opportunity to reduce the levels of professional-organizational conflict and thus, the undesirable consequences experienced during the recent severe nursing shortage [3].

Findings of a recent study including 27,509 nurses and 11,318 patients in the US conducted by Aiken et al. [10] suggest that cooperation of nursing professionals and their organizations in efforts to improve quality of care, safety and patient satisfaction and enhance nurses' work environments may have very promising effects for patients, nurses and their organizations. Overall, Aiken et al. [[10], p. 6] report "Hospitals with good work environments and better professional nurse staffing have more satisfied patients and nurses, and evidence of better quality and safety of care”.

The reduction of a degree of professional-organizational conflict in areas of major importance to nurses provides an opportunity, if not an incentive, for nurse leaders at all levels to ensure that nurses within the organization practice in an environment that encourages and supports their efforts to not only identify and respond effectively to ethical issues encountered in the course of their work, but also contribute significantly to meeting today's challenges of simultaneously improving outcomes, quality of care, safety, satisfaction and non-carethreatening cost containment as increasingly required by government, other payers and consumers. Nevertheless, despite this opportunity provided by a degree of congruence of professional and organizational goals, nurses and their leaders will continue to face an array of ethical issues. For example, a considerable degree of professional-organizational conflict will remain as organizational requirements of cost control continue to conflict with nurses' efforts to fulfill their professional ethical responsibilities. Nurses will also continue to encounter ethical issues associated with conflict between their personal and professional values and those of other providers, particularly those of doctors. While interprofessional conflict can be experienced throughout clinical practice, nurses' abilities to carry out their professional ethical obligation to advocate for the patient's best interest are most frequently encountered in cases involving end-of-life care, futile treatment and discussion of a patient's DNR status. Poor interprofessional collaboration has been found to lead not only to increased patient harm [11]-[13], but also moral distress for the nurse involved [14] [15], "increased economic cost of additional care for patients harmed by error as well as the costs of litigation” [14], reduction in patient satisfaction [16], and increased caregiver dissatisfaction and turnover [11]. As such, when nursing professionals encounter conflict between their personal and professional values and those of other providers, not only may both be inhibited from carrying out their ethical obligations effectively and exposed to related economic consequences, but the outcomes of poor collaboration may also conflict with the HCO's efforts to improve the quality of care, safety and 
patient satisfaction while continuing to reduce the cost of healthcare to qualify for reimbursement incentives or avoid penalties.

The article reports the findings of a survey of members of the American Organization of Nurse Executives (AONE) conducted in 2012 to determine the extent to which nurse leaders at different organization levels perceive various factors in their personal, professional and organizational environments to be helpful in resolving ethical dilemmas experienced at work. The findings of the 2012 survey are then compared with those from a similar survey conducted in 2000 at the height of the severe nurse shortage to determine the extent to which the relative helpfulness of factors encountered in HCOs today are perceived to have shifted from a decade ago. The authors also discuss the implications for the profession and the healthcare industry today and in the future.

\section{Data and Methodology}

In September 2012, 3000 members of AONE were surveyed by mail. Survey participants were selected at random from AONE's membership list and each received a 3-page questionnaire. Prior to the start of the study, an exempt application for research (IRB 2011-12031) was submitted to the Institutional Review Board at Drake University and approved 20 March 2012 with no expiration date. Since those participating in the survey were promised anonymity, a follow-up letter was sent to each nurse leader surveyed thanking those who had responded and requesting input from those who had not.

The questionnaire was developed by modifying the form used in the helps-challenges survey of AONE members conducted by Cooper, Frank, Gouty and Hansen [17] in 2000 (AONE 2000 helps-challenges survey). Survey modification was led by one of the authors and feedback regarding the revised form was sought from others in the local healthcare community as content experts. Based on discussion of the input received from these sources, an additional potential help factor-H14: a committee, team or individual in your organization who can be consulted to address ethical issues arising in an active clinical case-was added to the questionnaire for use in the 2012 AONE survey.

The questionnaire presented 18 statements (hereafter referred to as "helps") listed in Table 1. Using a Likert scale ( 5 = extremely helpful; 1 = not helpful), survey participants were asked to indicate how helpful each of the factors is in responding to ethical dilemmas encountered in their work. In cases where the potential help described was either not available or not applicable to them, participants were asked to indicate a sixth option (NA). An open-ended question asked the nurse leaders to indicate any other factors they find helpful in resolving ethical dilemmas. Demographic information was also gathered anonymously about the respondent and the organization for which they worked.

In terms of organization level, approximately 37 percent of the respondents completing the survey indicated they were either vice presidents (25 respondents), chief nurse executives, CNEs (14) or chief nursing officers, CNOs (62), 36 percent were directors (98), 15 percent were managers (41), 1 percent (2) were CEOs, 3 percent (7) were COOs, and 9 percent (24) indicated "other"-that is, other healthcare upper- or middle-management positions not identified in the survey.

With 37 surveys returned as undeliverable, responses were received from 274 of the 2963 AONE members (9.2\%). While the response rate is too low to permit generalizations to be made regarding the views of all nurse leaders, the findings are grounded in a sufficient number of responses to provide a sense of the key helps encountered in HCOs today as compared with a decade ago, and serve as a resource for further research related to factors that will enhance the strength of the ethical cultures experienced by nurses and other healthcare professionals in the future.

\section{Findings for 2012 Survey}

For each of the 18 potential help factors included in the 2012 study, Table 1 shows the mean of the ratings (other than "NA") given to that factor in response to the survey, its rank among all 18 helps based on the relative size of its mean, and the percentage of the respondents indicating "NA" (not available or not applicable to you) in rating that factor. Thus, for example, Help 12: ability to go to your boss for information and advice on ethical issues had a mean rating of 4.42 and ranked fourth among the 18 potential helps studied in terms of the extent to which it is helpful to those respondents not indicating "NA" in dealing with ethical dilemmas encountered at work. It was either not available or not applicable to 0.7 percent, less than one percent, of the survey respondents. 
Table 1. Ethical helps for nurse leaders in rank order: 2012.

\begin{tabular}{|c|c|c|c|c|c|}
\hline & Help & Mean & Rank & $\begin{array}{c}\text { Percent } \\
\text { indicating } 3 \text {, } \\
\quad 4 \text { or } 5\end{array}$ & $\begin{array}{l}\text { Percent } \\
\text { indicating } \\
\text { "NA" }\end{array}$ \\
\hline H17 & your own personal moral values and standards & 4.82 & 1 & 100.0 & 0.0 \\
\hline H15 & $\begin{array}{l}\text { the fact that your immediate boss does not pressure you into compromising } \\
\text { your ethical standards }\end{array}$ & 4.75 & 2 & 98.5 & 0.4 \\
\hline H11 & $\begin{array}{l}\text { an organizational environment/culture which does not encourage you to } \\
\text { compromise your ethical values to achieve organizational goals }\end{array}$ & 4.43 & 3 & 96.3 & 0.7 \\
\hline H12 & ability to go to your boss for information and advice on ethical issues & 4.42 & 4 & 95.9 & 0.7 \\
\hline H14 & $\begin{array}{l}\text { a committee, team or individual in your organization who can be consulted } \\
\text { to address ethical issues arising in an active clinical case }\end{array}$ & 4.42 & 4 & 96.7 & 1.5 \\
\hline H13 & $\begin{array}{l}\text { ability to go beyond your boss to higher level managers for information } \\
\text { and advice on ethical issues }\end{array}$ & 4.38 & 6 & 95.3 & 6.2 \\
\hline H8 & $\begin{array}{l}\text { a contact person in your organization to which you can report unethical } \\
\text { activity }\end{array}$ & 4.30 & 7 & 93.2 & 2.6 \\
\hline H9 & $\begin{array}{l}\text { a management philosophy in your organization which emphasizes ethics in } \\
\text { operations }\end{array}$ & 4.27 & 8 & 95.1 & 2.2 \\
\hline H10 & clear communication of appropriate ethical behavior by management & 4.27 & 8 & 95.2 & 1.1 \\
\hline H6 & your organization’s policy for identifying and resolving ethical issues & 4.13 & 10 & 95.5 & 2.2 \\
\hline H16 & help from your co-workers in resolving your ethical dilemmas & 4.13 & 10 & 95.9 & 0.4 \\
\hline $\mathrm{H} 2$ & literature on ethics/professionalism & 4.06 & 12 & 96.3 & 0.4 \\
\hline H3 & $\begin{array}{l}\text { professional publications/resources on ethics (e.g., AACN Standards of } \\
\text { Care) }\end{array}$ & 4.03 & 13 & 94.4 & 2.6 \\
\hline $\mathrm{H} 4$ & professional meetings where ethical issues can be discussed & 4.03 & 13 & 94.3 & 3.7 \\
\hline H18 & $\begin{array}{l}\text { your family and friends who provide support and insight for you in } \\
\text { resolving ethical conflicts }\end{array}$ & 3.97 & 15 & 92.6 & 5.5 \\
\hline H5 & your organization’s statement on ethics & 3.96 & 16 & 92.8 & 2.9 \\
\hline $\mathrm{H} 1$ & the current American Nurses Association Code of Ethics & 3.90 & 17 & 90.7 & 1.5 \\
\hline H7 & ethics training provided by your organization & 3.51 & 18 & 83.8 & 14.3 \\
\hline
\end{tabular}

\subsection{Overall Findings}

As indicated in Table 1, all the potential help factors have mean ratings greater than 3.0 (the midpoint on the rating scale), suggesting that the responding nurse leaders tend to find these resources to be reasonably helpful to them in dealing with ethical dilemmas.

The potential helps listed in the survey questionnaire can be classified into the three groups of factors that as mentioned earlier, have been found to influence ethical decision making and behavior of those working in organizations - those related to one's:

- personal attributes/environment (Helps 17 and 18);

- organizational environment (Helps 5 through 16), and

- professional environment (Helps 1 through 4).

The mean ratings in Table 1 indicate how the respondents tend to perceive the relative helpfulness of factors related to their personal, organizational and professional environments in attempting to behave ethically in the course of their work. As might be expected, they find their own personal moral values and standards (Help 17) to be the most helpful resource available for dealing with ethical dilemmas.

Next, the respondents tend to look to certain aspects of their organizational environment (rather than to resources related to the professional environment) for help in dealing with ethical dilemmas encountered in their work. After their personal values and standards, the remaining factors ranked in the top-10 in terms of helping responding nurse leaders deal with ethical issues relate to their organizational environment. While three of the organization-related helps in the top 10 are formal organizational factors (H6, H8 and H14), the remaining organization-related helps in the top 10 arise from the more informal organizational climate. The key factors related to organizational climate include the actions and responsiveness of one's immediate boss as well as the 
ability to go beyond one's boss if necessary, the organizational culture, management philosophy, management's communication of appropriate ethical behavior and help from one's co-workers.

The highest rated business-related factor is Help 15: the fact that your immediate boss does not pressure you into compromising your ethical standards. Rated next is Help 11: an organizational environment/culture that does not encourage you to compromise your ethical values to achieve organizational goals. Both of these factors deal with the absence of pressure to compromise one's own ethical standards. This suggests that one way HCOs can assist nurses and their leaders is by neither explicitly nor implicitly pressuring them to go against their own ethical values.

In contrast, two formal organization-related factors-H5: your organization's statement on ethics, and H7: ethics training provided by your organization - were not included in the top $10 \mathrm{in}$ terms of their helpfulness to the responding nurse leaders in dealing with ethical issues encountered in their work. The relatively low ranking of $\mathrm{H} 5$ is consistent with the findings of a meta-analysis conducted by Kish-Gephart et al. [[18], p. 21] that indicate the "mere existence of a code of conduct has no detectable impact on unethical choices." However, Kish-Gephart et al. [[18], p. 21] indicate, "As our results revealed, a properly enforced code of conduct can have a powerful influence on unethical choices".

Also, noteworthy is the ranking of ethics training provided by one's organization as least helpful among the 18 potential helps. This is congruent with the findings of other data collected in the survey indicating that "a lack of ethics training in your organization" ranked third among 21 factors presenting potential challenges to efforts of responding nurse leaders to act ethically in the course of their work.

Although the four help factors $(\mathrm{H} 1-\mathrm{H} 4)$ related to the professional environment-the current American Nurses Association (ANA) Code of Ethics [19], literature on ethics/professionalism, professional publications and resources such as the American Association of Critical-Care Nurses (AACN) Standards of Care, and professional meetings where ethical issues can be discussed — were viewed as helpful to the nurse leaders responding to the survey, they were rated below all but two of the business-related factors (H5 and H7) in terms of their helpfulness to the respondents.

\subsection{Subgroup Analysis}

With the few exceptions shown in Table 2, no statistically significant differences were found in the mean ratings (at the 0.05 level) for the vast majority of the help factors when responding nurse leaders were grouped by certified versus not certified by the American Nurses Credentialing Center or AONE, position title, highest education degree, age, gender, profit versus not for profit HCOs, public versus private HCOs, existence versus nonexistence of an ethics committee in their organization and scope of the ethics committee. In addition, no significant differences at all were found in the mean ratings for the helps when the respondents were grouped by credential(s) held (NE-BC, NEA-BC, CENP and CNML), bed size and AONE region to which they belong.

\subsection{Ethical Helps 2012 versus 2000 Findings}

As mentioned earlier, an additional potential help factor-H14: a committee, team or individual in your organization who can be consulted to address ethical issues arising in an active clinical case-not included in the AONE 2000 study was added to the questionnaire used in the 2012 survey. Table 3 shows the 2012 and 2000 means and ranks for the 17 help factors common to both studies listed in the order of the 2012 helps.

Comparison of the findings indicates a number of similarities. In both studies, the top-4 helps are identical and ranked in the same order. Despite some differences in ranking, the top-10 help factors are also identical. A strong positive correlation coefficient for the means, 0.853 (significant at the 0.01 level), indicates that the order of the 17 help factors common to both studies is quite similar overall.

There are also several differences in the findings of the 2012 and 2000 helps studies. As indicated in Table 3, three factors related to the organizational environment (H8, H13 and H15) were viewed as being significantly more helpful to the respondents in the 2012 study than to those in the study conducted in 2000. On the other hand, H7, ethics training provided by your organization, was viewed as significantly less helpful in dealing with ethical issues in 2012 than in 2000. Two profession-related factors, H1: the current ANA Code of Ethics and H3: professional publications were viewed as significantly more helpful to responding nurse leaders in the 2012 study than to those in the earlier study. Nevertheless, despite the perceived increase in the helpfulness of the ANA Code of Ethics, it remained very near the bottom of the list in terms of its relative helpfulness. 
Table 2. Statistically significant ${ }^{*}$ differences for subgroup helps means.

\begin{tabular}{|c|c|c|}
\hline Sub group & Help & Significant difference \\
\hline \multirow[t]{2}{*}{ Certification } & $\begin{array}{l}\text { H1: the current American Nurses Association Code } \\
\text { of Ethics }\end{array}$ & $\begin{array}{l}\text { More helpful to those who are certified than to those who } \\
\text { are not }\end{array}$ \\
\hline & $\begin{array}{l}\text { H8: a contact person in your organization to which } \\
\text { you can report unethical activity }\end{array}$ & $\begin{array}{l}\text { More helpful to those who are not certified than to those } \\
\text { who are }\end{array}$ \\
\hline \multirow[t]{5}{*}{ Position title } & H7: ethics training provided by your organization & More helpful to COOs than to vice presidents \\
\hline & $\begin{array}{l}\text { H9: a management philosophy in your organization } \\
\text { which emphasizes ethics in operations }\end{array}$ & More helpful to COOs than to managers and directors \\
\hline & $\begin{array}{l}\text { H13: ability to go beyond your boss to higher level } \\
\text { managers for information and advice on ethical } \\
\text { issues }\end{array}$ & More helpful to COOs than to managers \\
\hline & $\begin{array}{l}\text { H16: help from your co-workers in resolving } \\
\text { ethical dilemmas }\end{array}$ & $\begin{array}{l}\text { More helpful to COOs than to those in other healthcare } \\
\text { upper or middle management positions not identified in the } \\
\text { survey }\end{array}$ \\
\hline & $\begin{array}{l}\text { H18: your family and friends who provide support } \\
\text { and insight for you in resolving ethical conflicts }\end{array}$ & $\begin{array}{l}\text { More helpful to managers than to vice presidents and those } \\
\text { in other healthcare upper or middle management positions } \\
\text { not identified in the survey }\end{array}$ \\
\hline \multirow[t]{3}{*}{$\begin{array}{l}\text { Highest education } \\
\quad \text { degree }\end{array}$} & $\begin{array}{l}\text { H11: an organizational/culture which does not } \\
\text { encourage you to compromise your ethical values } \\
\text { to achieve organizational goals }\end{array}$ & $\begin{array}{l}\text { More helpful to those with a Master's degree than to those } \\
\text { with a BSN degree }\end{array}$ \\
\hline & $\begin{array}{l}\text { H13: ability to go beyond your boss to higher level } \\
\text { managers for information and advice on ethical } \\
\text { issues }\end{array}$ & $\begin{array}{l}\text { More helpful to those with a Master's degree than to those } \\
\text { with a BSN degree }\end{array}$ \\
\hline & $\begin{array}{l}\text { H15: the fact that your immediate boss does not } \\
\text { pressure you into compromising your ethical } \\
\text { standards }\end{array}$ & $\begin{array}{l}\text { More helpful to those with a Master's degree than to those } \\
\text { with a BSN degree }\end{array}$ \\
\hline Age & $\begin{array}{l}\text { H8: a contact person in your organization to which } \\
\text { you can report unethical activity }\end{array}$ & $\begin{array}{l}\text { More helpful to those whose ages are } 60 \text { - } 69 \text { than to those } \\
\text { whose ages are } 70-79\end{array}$ \\
\hline Gender & $\begin{array}{l}\text { H15: the fact that your immediate boss does not } \\
\text { pressure you into compromising your ethical } \\
\text { standards }\end{array}$ & More helpful to males than females \\
\hline Type of HCO & H3: professional publications/resources on ethics & $\begin{array}{l}\text { More helpful to those employed by government HCOs than } \\
\text { to those employed by for-profit HCOs }\end{array}$ \\
\hline \multirow[t]{4}{*}{ Ethics committee } & $\begin{array}{l}\text { H6: your organization's policy for identifying and } \\
\text { resolving ethical issues }\end{array}$ & $\begin{array}{l}\text { More helpful to those whose organization has an ethics } \\
\text { committee than to those whose organization does not }\end{array}$ \\
\hline & $\begin{array}{l}\text { H8: a contact person in your organization to which } \\
\text { you can report unethical activity }\end{array}$ & $\begin{array}{l}\text { More helpful to those whose organization has an ethics } \\
\text { committee than to those whose organization does not }\end{array}$ \\
\hline & $\begin{array}{l}\text { H9: a management philosophy in your organization } \\
\text { which emphasizes ethics in operations }\end{array}$ & $\begin{array}{l}\text { More helpful to those whose organization has an ethics } \\
\text { committee than to those whose organization does not }\end{array}$ \\
\hline & $\begin{array}{l}\text { H13: ability to go beyond your boss to higher level } \\
\text { managers for information and advice on ethical } \\
\text { issues }\end{array}$ & $\begin{array}{l}\text { More helpful to those whose organization has an ethics } \\
\text { committee than to those whose organization does not }\end{array}$ \\
\hline \multirow[t]{3}{*}{$\begin{array}{l}\text { Scope of the } \\
\text { ethics committee }\end{array}$} & $\begin{array}{l}\text { H1: the current American Nurses Association Code } \\
\text { of Ethics }\end{array}$ & $\begin{array}{l}\text { More helpful to those whose organization has only a clinical } \\
\text { ethics committee or both a clinical and an organizational } \\
\text { ethics committee than to those whose organization has only } \\
\text { an organizational ethics committee }\end{array}$ \\
\hline & H2: literature on ethics/professionalism & $\begin{array}{l}\text { More helpful to those whose organization has only a clinical } \\
\text { ethics committee or both a clinical and an organizational } \\
\text { ethics committee than to those whose organization has only } \\
\text { an organizational ethics committee }\end{array}$ \\
\hline & H3: professional publications/resources on ethics & $\begin{array}{l}\text { More helpful to those whose organization has only a clinical } \\
\text { ethics committee or both a clinical and an organizational } \\
\text { ethics committee than to those whose organization has only } \\
\text { an organizational ethics committee }\end{array}$ \\
\hline
\end{tabular}

\footnotetext{
${ }^{*}$ Significant at the 0.05 level.
} 
Table 3. Common ethical helps for nurse leaders by 2012 rank order: 2012 versus 2000.

\begin{tabular}{|c|c|c|c|c|c|}
\hline & \multirow{2}{*}{ Help } & \multicolumn{2}{|c|}{$2012(\mathrm{~N}=274 ; 9.3 \%)$} & \multicolumn{2}{|c|}{$2000(\mathrm{~N}=426 ; 21.3 \%)$} \\
\hline & & Mean & Rank & Mean & Rank \\
\hline H17 & your own personal moral values and standards & 4.82 & 1 & 4.79 & 1 \\
\hline H15 & $\begin{array}{l}\text { the fact that your immediate boss does not pressure you into } \\
\text { compromising your ethical standards }\end{array}$ & $4.75^{*}$ & 2 & 4.58 & 2 \\
\hline H11 & $\begin{array}{l}\text { an organizational environment/culture which does not encourage you } \\
\text { to compromise your ethical values to achieve organizational goals }\end{array}$ & 4.43 & 3 & 4.47 & 3 \\
\hline H12 & ability to go to your boss for information and advice on ethical issues & 4.42 & 4 & 4.36 & 4 \\
\hline H13 & $\begin{array}{l}\text { ability to go beyond your boss to higher level managers for } \\
\text { information and advice on ethical issues }\end{array}$ & $4.38^{*}$ & 5 & 4.15 & 7 \\
\hline H8 & $\begin{array}{l}\text { a contact person in your organization to which you can report } \\
\text { unethical activity }\end{array}$ & $4.30^{*}$ & 6 & 4.13 & 9 \\
\hline H9 & $\begin{array}{l}\text { a management philosophy in your organization which emphasizes } \\
\text { ethics in operations }\end{array}$ & 4.27 & 7 & 4.30 & 5 \\
\hline H10 & clear communication of appropriate ethical behavior by management & 4.27 & 7 & 4.25 & 6 \\
\hline H6 & your organization's policy for identifying and resolving ethical issues & 4.13 & 9 & 4.14 & 8 \\
\hline H16 & help from your co-workers in resolving your ethical dilemmas & 4.13 & 9 & 4.12 & 10 \\
\hline $\mathrm{H} 2$ & literature on ethics/professionalism & 4.06 & 11 & 4.00 & 13 \\
\hline H3 & $\begin{array}{l}\text { professional publications/resources on ethics (e.g., AACN Standards } \\
\text { of Care) }\end{array}$ & $4.03^{*}$ & 12 & 3.81 & 15 \\
\hline $\mathrm{H} 4$ & professional meetings where ethical issues can be discussed & 4.03 & 12 & 4.10 & 11 \\
\hline H18 & $\begin{array}{l}\text { your family and friends who provide support and insight for you in } \\
\text { resolving ethical conflicts }\end{array}$ & 3.97 & 14 & 3.91 & 14 \\
\hline H5 & your organization's statement on ethics & 3.96 & 15 & 4.01 & 12 \\
\hline $\mathrm{H} 1$ & the current American Nurses Association Code of Ethics & $3.90^{*}$ & 16 & 3.33 & 17 \\
\hline H7 & ethics training provided by your organization & 3.51 & 17 & $3.78^{* *}$ & 16 \\
\hline
\end{tabular}

${ }^{*}=$ AONE 2012 mean significantly greater at the 0.05 level than the AONE 2000 mean. ${ }^{* *}=$ AONE 2000 mean significantly greater at the 0.05 level than the AONE 2012 mean.

\section{Discussion}

With ethical decision making and behavior of nurses' employed in healthcare organizations influenced by factors from their personal, professional and organizational environments and lack of congruence of perceived values in these areas leading to ethical conflict, the study examined the extent to which various factors from each of these three areas were viewed as being helpful to nurse leaders in dealing with ethical issues encountered in their work. The personal, professional and organizational factors were all perceived as helpful to the survey participants when faced with ethical dilemmas. The findings indicate that after their own personal moral values and standards, the responding nurse leaders turn next for help to various factors related to their organization's ethical environment reflecting the interaction of formal programs with less tangible elements of organizational climate. As examples of the latter, the two most helpful organizational factors involve an immediate boss and an organizational environment/culture that do not pressure an employee to compromise their ethical standards.

While viewed as helpful to the responding nurse leaders, factors related to the profession were perceived as being less helpful than those related to the organizational environment. The relatively low ranking of factors related to the professional environment, especially the current ANA Code of Ethics which ranked seventeenth among the 18 factors studied, suggests an opportunity for nursing professional associations to develop even more effective ethics related resources for use by their members.

The relatively higher ranking of organizational factors as compared with professional factors may be a reflection of the existence of professional-organizational conflict in HCOs. When experienced by nurses employed in an organization, professional-organizational conflict reflects incongruence between the accepted values of nursing professionals and the organization's perceived values considered unacceptable by the professionals. In such a case, an effort by nurses to reduce conflict so as to permit implementation of programs, procedures or activi- 
ties aimed at enabling them to meet their professional responsibilities requires primary focus on evaluating and dealing with the conflicting values encountered in the organizational environment.

Analysis of the data gathered for each of the 18 helps factors revealed relatively few, if any, statistically significant differences among the means for each of the various subgroups studied. The findings related to position titles are noteworthy. As indicated in Table 2, statistically significant differences were found for only four organizational factors- H7, H9, H13 and H16. In each case, the organizational factor was found to be more helpful to COOs than to respondents in certain other subgroups more directly involved in managing nursing operations. Since there were no statistically significant differences found among those holding various nursing management positions, introduction of an ethical environment within the nursing division based on the 18 personal, professional and organizational factors studied would appear likely to be acceptable to nurse leaders affected and thus, serve as basis for encouraging and supporting ethical behavior of nurses throughout the organization.

Noteworthy significant differences were also found between the means for two other subgroups studied. As indicated in Table 2, respondents who held a Master's degree perceived three highly rated organizational factors- H15, H11 and H13 - as being significantly more helpful in dealing with ethical challenges than did those whose highest degree held was a BSN. Also as indicated in Table 2, respondents whose organization has an ethics committee perceived four organizational factors-H13, H8, H9 and H6-as being significantly more helpful than those whose organization does not.

Comparison of the findings of the 2012 helps study with those of a similar study conducted in 2000 indicates a number of similarities and differences. The top-4 most helpful factors were identical with the same rank order in both studies and the top-10 factors were identical with some differences in ranking. Further analysis indicated the relative degree of helpfulness of the 17 help factors common to both studies was perceived by responding nurse leaders as quite similar overall.

The findings regarding the helpfulness of ethics training provided by the responding nurse leaders' organizations raises two concerns. In both studies, ethics training was viewed as either the least or next to the least helpful factor in responding to ethical dilemmas encountered by the respondents in their work. Moreover, despite the increased need for all types of training during the current reform of the healthcare system, responding nurse leaders indicated ethical training provided by their organizations today is significantly less helpful than that provided 12 years ago. Without adequate training, nurses will encounter difficulties in identifying and resolving ethical issues as well as in making recommendations regarding innovative approaches for efficiently improving the quality of care, safety and patient satisfaction throughout the organization.

\section{Conclusions}

In recent years, demands by payers that HCOs raise their standards for patient care, safety and satisfaction while continuing their efforts to reduce the cost of healthcare have created a degree of congruence of organizational values with those long espoused by nursing professionals. Reduction in the level of professional-organizational conflict has produced an opportunity for nurse leaders at all levels to ensure that nurses within the organization practice in an environment that encourages and supports their efforts to not only identify and respond effectively to ethical issues encountered in the course of their work, but also contribute significantly to meeting today's challenges associated with simultaneously improving outcomes, quality of care, safety, satisfaction and noncare-threatening cost containment. The findings of the 2012 helps survey suggest nurse leaders have an important role to play in creating and growing an ethical culture to support these efforts in their organizations.

Overall, survey results indicated that responding nurse leaders perceived all 18 factors related to their personal, professional and organizational environments as being helpful in dealing with ethical issues encountered at work. After their own personal moral values, nurse leaders indicated that with two exceptions-their organization's statement on ethics and ethics training by their organization, factors related to their organizational environment are more helpful than professional resources in responding to ethical dilemmas. The findings have several implications for the nursing profession as well as the health care industry. First, the greater helpfulness of organizational factors as compared with those from the profession suggest HCOs must take the lead in establishing and maintaining an ethical workplace for nursing professionals they employ. The similarity of the top- 10 factors in both the 2000 and 2012 studies suggest responding nurse leaders perceive the same factors as being most helpful in dealing with ethical challenges over time. Second, as suggested by the two most helpful organization related factors, HCOs may be able to improve ethical behavior by simply not pressuring employees to compromise their own values. Third, HCOs can help nurses make ethical choices by encouraging them to go to 
their boss and even higher level managers for information and advice on ethical issues. This also requires the organization to ensure that managers at various levels are properly prepared to meet these responsibilities. Fourth, with no significant differences found in the extent to which each of the organizational factors and professional factors were perceived as being helpful by survey respondents in positions below those serving as COOs, efforts of other nurse leaders in establishing and growing an ethical culture for nursing operations may be less problematic than might otherwise be the case. Fifth, while an organization's statement on ethics alone is ranked as one of the least helpful factors, research indicates that when a code of conduct is properly enforced it can have a very positive influence on ethical decision making by employees [18]. Finally, with ethics training provided by their organization ranked as the least helpful factor at a time with such extensive change occurring in the healthcare industry, HCOs must improve such training if they are to meet requirements for improved patient care, safety and satisfaction as well as avoid harmful effects on organizational commitment, job satisfaction and turnover. This need for improved training also provides an opportunity for the profession to improve the helpfulness of its resources.

\section{References}

[1] Craft, J.L. (2013) A Review of the Empirical Ethical Decision Making Literature: 2004-2011. Journal of Business Ethics, 117, 221-259. http://dx.doi.org/10.1007/s10551-012-1518-9

[2] Cowton, C.J. (2009) Accounting and Ethics Challenge: Remembering the Professional Body. Accounting and Business Research, 39, 177-189. http://dx.doi.org/10.1080/00014788.2009.9663359

[3] Shafer, W.E. (2002) Ethical Pressure, Organizational-Professional Conflict, and Related Work Outcomes among Management Accountants. Journal of Business Ethics, 38, 263-275.

[4] Hussain, A., Rivers, P.A., Glover, S. H. and Fottler, M. D. (2012) Strategies for Dealing with Future Shortages in the Nursing Workforce: A Review. Health Services Management Research, 25, 41-47. http://dx.doi.org/10.1258/hsmr.2011.011015

[5] Gage, L. (2012) Transformational Governance: Best Practices for Public and Nonprofit Hospitals and Health Systems. Center for Healthcare Governance of the American Hospital Association, Chicago. http://www.americangovernance.com/resources/reports/transformational-governance/

[6] Needleman, J. and Hassmiller, S. (2009) The Role of Nurses in Improving Hospital Quality and Efficiency: RealWorld Results. Health Affairs, 28, w625-w633. http://dx.doi.org/10.1377/hlthaff.28.4.w625

[7] Raso, R. (2013) Value-Based Purchasing: What's the Score. Nursing Management, 44, 28-34. http://dx.doi.org/10.1097/01.NUMA.0000429001.54893.bb

[8] Rau, J. (2013) Nearly 1500 Hospitals Penalized Under Medicare Program Rating Quality. http://www.kaiserhealthnews.org/Stories/2013/November/14/value-based-purchasing-medicare.aspx

[9] Ryan, A.M. (2013) Will Value-Based Purchasing Increase Disparities in Care? New England Journal of Medicine, 369, 2472-2474. http://dx.doi.org/10.1056/NEJMp1312654

[10] Aiken, L.H., Sermeus, W., Van den Heede, K., et al. (2012) Patient Safety, Satisfaction, and Quality of Hospital Care: Cross Sectional Surveys of Nurses and Patients in 12 Countries in Europe and The United States. British Medical Journal, 344, 1-14. http://dx.doi.org/10.1136/bmj.e1717

[11] Rose, L. (2011) Interprofessional Collaboration in the ICU: How to Define. Nursing in Critical Care, 16, 5-10. http://dx.doi.org/10.1111/j.1478-5153.2010.00398.x

[12] Reader, T., Flin, R.K., Mearns, K. and Cuthbertson, B. (2007) Interdisciplinary Communication in the Intensive Care Unit. British Journal of Anaesthesia, 98, 347-352. http://dx.doi.org/10.1093/bja/ael372

[13] Zwarenstein, M., Goldman, J. and Reeves, S. (2009) Interprofessional Collaboration: Effects of Practice-Based Interventions on Professional Practice and Healthcare Outcomes. Cochrane Database of Systematic Reviews, 8, Article ID: CD000072. http://dx.doi.org/10.1002/14651858.CD000072.pub2

[14] Engel, J. and Prentice, D. (2013) The Ethics of Interprofessional Collaboration. Nursing Ethics, 20, 426-435. http://dx.doi.org/10.1177/0969733012468466

[15] Robichaux, C. and Sauerland, J. (2012) Health Care Quality and Ethics: Implications for Practice and Leadership. Perioperative Nursing Clinics, 7, 333-342. http://dx.doi.org/10.1016/j.cpen.2012.06.002

[16] American Association of Critical-Care Nurses (AACN) (2005) AACN Standards for Establishing and Sustaining Healthy Work Environments: A Journey to Excellence. http://www.aacn.org/wd/hwe/docs/hwestandards.pdf

[17] Cooper, R.W., Frank, G.L., Gouty, C.A. and Hansen, M.M. (2003) Ethical Helps and Challenges Faced by Nurse Leaders in the Healthcare Industry. Journal of Nursing Administration, 33, 17-23. 
http://dx.doi.org/10.1097/00005110-200301000-00005

[18] Kish-Gephart, J.J., Harrison, D.A. and Trevino, L.K. (2010) Bad Apples, Bad Cases, and Bad Barrels: Meta-Analytic Evidence about Sources of Unethical Decisions at Work. Journal of Applied Psychology, 95, 1-31. http://dx.doi.org/10.1037/a0017103

[19] American Nurses Association (ANA) (2001) Code of Ethics for Nurses with Interpretive Statements. http://www.nursingworld.org/MainMenuCategories/EthicsStandards/CodeofEthicsforNurses/Code-of-Ethics.pdf 
Scientific Research Publishing (SCIRP) is one of the largest Open Access journal publishers. It is currently publishing more than 200 open access, online, peer-reviewed journals covering a wide range of academic disciplines. SCIRP serves the worldwide academic communities and contributes to the progress and application of science with its publication.

Other selected journals from SCIRP are listed as below. Submit your manuscript to us via either submit@scirp.org or Online Submission Portal.
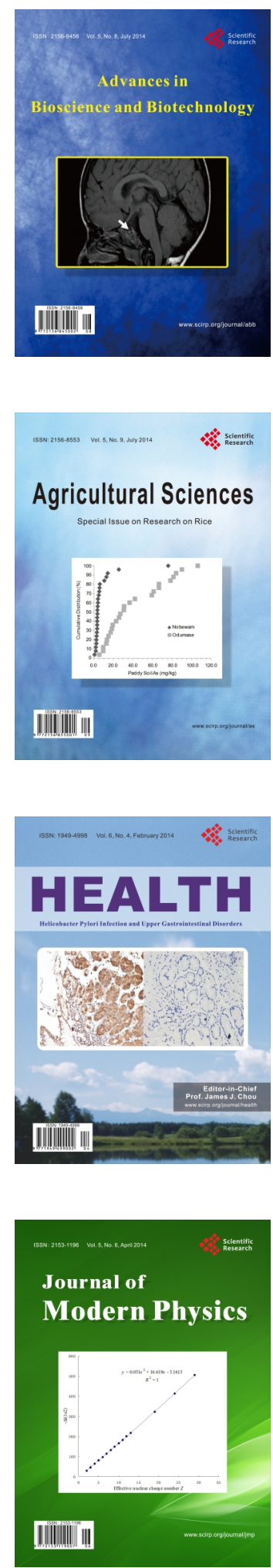
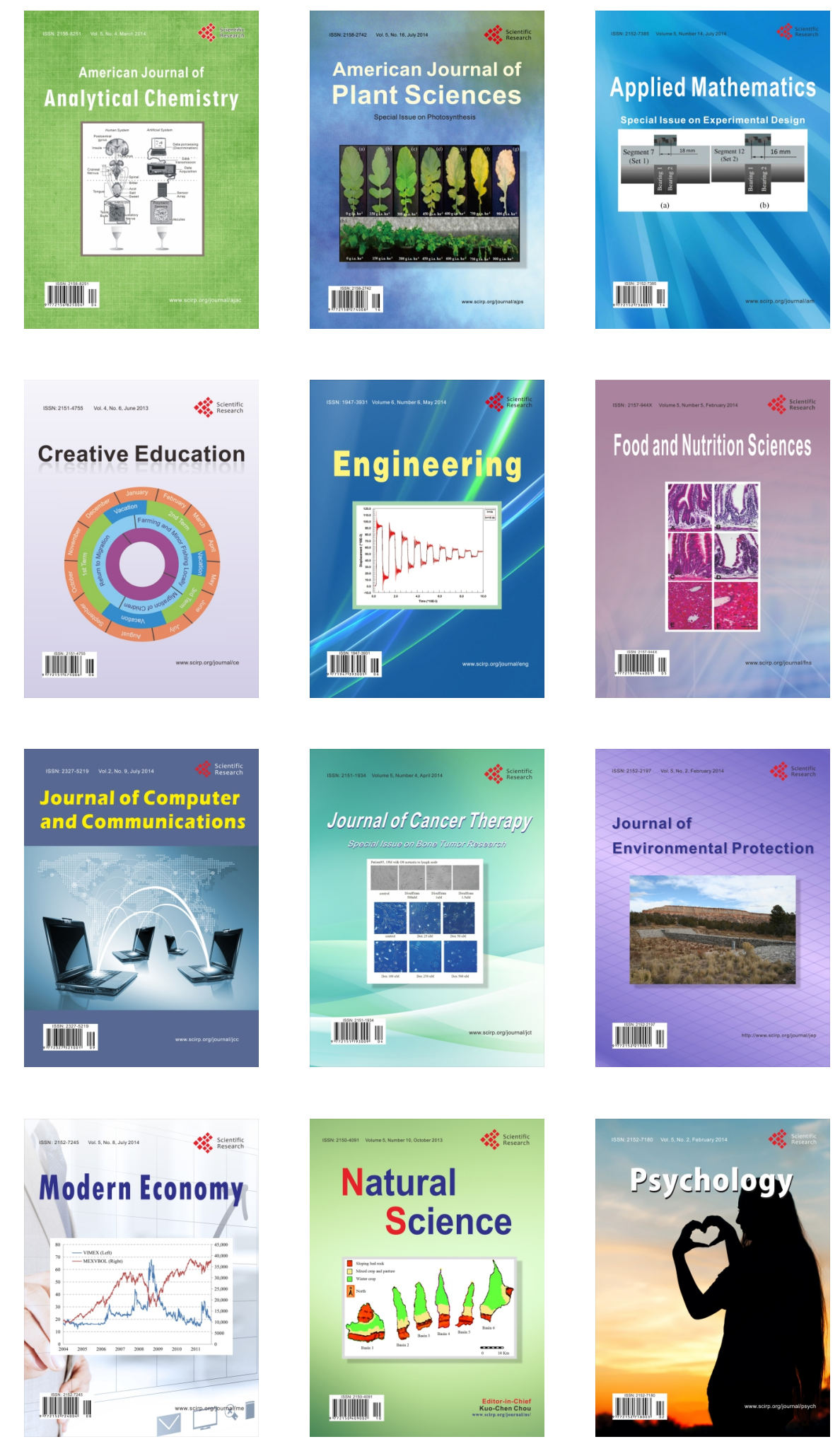